\title{
Erratum
}

\section{Synthesis of the Hypoxic Signaling Inhibitor Furospongolide}

John Boukouvalas, * Vincent Albert Synlett 2011, 2541.

The advance online publication (e-first) version of this article contained errors in Scheme 2. For the synthesis of compound 12 wrong reagents were given. The correct ones are $7 \mathbf{a}, \mathrm{PdCl}_{2}\left(\mathrm{PPh}_{3}\right)_{2}, \mathrm{CuI}, i$ - $\mathrm{Pr}_{2} \mathrm{NEt}$, dioxane.

All errors have been corrected for both the current online version and the print publication. We apologize for these mistakes. 